\title{
Acute abdominal pain and nephrotic syndrome: pediatric case reports and review of the literature
}

\author{
Giovanni Conti ${ }^{1 *}$, Nicolina Stefania Carucci ${ }^{1}$, Valentina Comito ${ }^{1}$, Pietro Impellizzeri ${ }^{2}$, Carmela Visalli ${ }^{3}$, \\ Claudia Ventrici ${ }^{1}$, Roberto Chimenz ${ }^{1}$ and Carmelo Romeo ${ }^{2}$
}

\begin{abstract}
Background: Acute abdominal pain in nephrotic syndrome (NS) is a well-known clinical symptom and is mainly related to peritonitis. The presence, although rare, of red umbilicus may guide the diagnosis as a suggestive sign of peritonitis also in the non-neonatal period. Instead, the association between intussusception and NS is quite limited. We reviewed all published cases in the literature, and to our knowledge, this is one of the few pediatric cases of spontaneous resolution of intussusception in the setting of NS. Finally, a review of the causes of abdominal pain during the course of NS was made.

Cases presentation: We report two pediatric patient cases who complained of acute abdominal pain during a relapse episode of their NS. The first case is a 4-year-old boy with NS (fourth relapse) who presented with acute abdominal pain, ascites, and red umbilicus. Our suspect of primary peritonitis was clinically confirmed because of the subsequent appearance of the classical peritoneal signs. The second case is a 4-year-old boy who developed an ileo-ileal intussusception during the treatment of his first NS relapse, with spontaneous reduction.

Conclusions: Gastrointestinal disorders are frequently encountered in the course of NS. The appearance of acute abdominal pain in children with NS requires quick management, both clinical and instrumental. A multidisciplinary team approach needs to be encouraged to lead to an accurate diagnosis and a correct treatment.
\end{abstract}

Keywords: Nephrotic syndrome, Pediatric case reports, Acute abdominal pain, Peritonitis, Intussusception

\section{Background}

Nephrotic syndrome (NS) is one of the most common pediatric glomerular diseases, with an incidence of around 2-7 cases per 100,000 children per year. Renal histology reveals the presence of minimal change disease (MCD) in about $76 \%$ of these patients while only 10 $20 \%$ of them show focal segmental glomerulosclerosis. Subjects with MCD have a 95\% response rate to steroids; however, $75 \%$ will relapse and $50 \%$ (frequent relapsers or steroid-dependent subjects) will require higher and

\footnotetext{
* Correspondence: giovanniconti@hotmail.com

'Pediatric Nephrology and Rheumatology Unit, Department of Human Pathology in Adult and Developmental Age "Gaetano Barresi," AOU Gaetano Martino, University of Messina, Via Consolare Valeria, 98124 Messina, Italy Full list of author information is available at the end of the article
}

prolonged doses of steroids thus increasing the risk of side effects [1-3]. Idiopathic forms have a higher incidence in the pediatric population; conversely, in adults, it is mandatory to exclude secondary forms because they are the most frequent [4]. The cause remains unknown but the pathogenesis of idiopathic NS is thought to involve immune dysregulation, systemic circulating factors, or inherited structural abnormalities of the podocyte [5]. NS is defined by the presence of heavy proteinuria $(\geq 50$ $\mathrm{mg} / \mathrm{kg} /$ day or $\geq 40 \mathrm{mg} / \mathrm{m}^{2} / \mathrm{h}$ ) or a proteinuria/creatininuria ratio $(>2 \mathrm{mg} / \mathrm{mg})$, hypoalbuminemia $(<2.5 \mathrm{~g} / \mathrm{dl})$, and edema [1]. Complications of NS may occur as a part of the disease itself (because of the large loss of plasma proteins in the urine) or as a consequence of drug treatment (corticosteroids, cyclophoshamide, calcineurin 
inhibitors, mycophenolate mofetil). Disease-associated complications include infections, thromboembolism, hypovolemic crisis, cardiovascular problems, acute renal failure, anemia, and hormonal and mineral alterations [6].

We report two unusual cases of NS-related abdominal disease (one case of primary peritonitis and one of intussusception), describing their clinical presentation and their management as notable complications in nephrotic patients. In addition, we carefully reviewed the literature concerning acute gastrointestinal disorders during NS. It is widely reported that acute abdominal pain is a relatively common feature in patients with NS. The clinical picture, along with blood and instrumental tests, can help clinicians to make a differential diagnosis and to determine the suspected condition. Among the several causes of abdominal pain in the setting of NS, pediatric nephrologists should consider spontaneous bacterial peritonitis, especially if fever is present [5], and intussusception, less common, but remarkable disease, whose early recognition may improve prognosis [7].

\section{Case presentation}

A Caucasian 4-year-old boy was admitted to our unit for the fourth relapse of his steroid-dependent NS. He was diagnosed as having idiopathic NS at 3 years of age. The third relapse happened about 40 days before the last one and was treated with oral prednisone $\left(60 \mathrm{mg} / \mathrm{m}^{2} /\right.$ day $)$ with rapid remission of proteinuria, but as soon as we tried to switch to alternate-day prednisone therapy, the fourth relapse happened. At the admission, the patient showed facial swelling, peripheral (scrotal and pretibial) edema, and ascites with a 2-kg weight gain. His body temperature was $36.7^{\circ} \mathrm{C}$, heart rate 100 beats $/ \mathrm{min}$, respiratory rate 21 breaths/min, and blood pressure 115/ $75 \mathrm{mmHg}$. Blood tests revealed the following: total proteins $3.9 \mathrm{~g} / \mathrm{dl}$, serum albumin $1.3 \mathrm{~g} / \mathrm{dl}$, serum sodium concentration $125 \mathrm{mmol} / \mathrm{l}$, potassium $5.7 \mathrm{mmol} / \mathrm{l}$, and calcium $7.6 \mathrm{mg} / \mathrm{dl}$. Urine volume was $650 \mathrm{ml} / 24 \mathrm{~h}$ with severe proteinuria $(15.6 \mathrm{~g} / 24 \mathrm{~h})$. The summary of all investigations is shown in Table 1 .
A decision was made to start intravenous methylprednisolone pulse therapy, at a dosage of $10 \mathrm{mg} / \mathrm{kg} /$ day for 3 consecutive days, together with calcium gluconate and albumin infusion. About $48 \mathrm{~h}$ after the beginning of this treatment, the boy gradually showed severe generalized abdominal pain without initial signs of peritoneal inflammation. The periumbilical area was abnormal in its appearance: erythema was centralized within the umbilicus and extended $1.5 \mathrm{~cm}$ about the entire umbilicus. A few hours later, we documented a sudden worsening of the clinical conditions. A pediatric surgical consult was required and confirmed the patient's serious conditions, with the following features: marked abdominal distension, ascites, diffuse tenderness to superficial and deep palpation, hypoactive bowel sounds, and positive Blumberg's sign. The child laid up in a semi-sitting position with superficial breathing. No fever or vomiting was documented. The umbilical erythema gradually developed all around the umbilical area that became severely painful at palpation but did not show any mass or purulent discharge. Emergency blood tests suggested a bacterial infection. An abdominal X-ray demonstrated a paralytic ileus with severe gastrectasia, several air-fluid levels, and an abnormal gas pattern with no intestinal loops visualized. An abdominal ultrasound showed a considerable amount of "corpusculated" fluid and distention of small bowel loops especially in correspondence of the umbilical region. Despite the increase of D-dimer $(4.5 \mu \mathrm{g} / \mathrm{ml}$, normal $<0.5 \mu \mathrm{g} / \mathrm{ml})$, mesenteric and renal vascular flows were normal. Physical, laboratory, and radiological findings suggested the hypothesis of primary peritonitis. Considering that the timing and worsening of the clinical presentation could have been influenced by the immunosuppressive treatment of the patient, in agreement with the pediatric surgeon, a conservative approach was carried out starting the patient on empirical antibiotic treatment with intravenous broad-spectrum antibiotics to cover resistant pneumococci and bowel organisms: metronidazole $(7.5 \mathrm{mg} / \mathrm{kg}$ every $8 \mathrm{~h})$ and ceftazidime $(100 \mathrm{mg} / \mathrm{kg} /$ day $)$. The paracentesis was delayed in case of no antibiotic response. The steroid treatment was suspended. Furthermore, enteral feeding was

Table 1 Summary of investigations (*beginning of the antibiotic treatment)

\begin{tabular}{|c|c|c|c|c|c|c|}
\hline Day of hospitalization & Day 1 & Day 3* & Day 4 & Day 5 & Day 6 & Day 10 \\
\hline White cell count $\left(\mathrm{mm}^{3}\right)$ & 10,000 & 19,400 & 23,000 & 18,000 & 15,000 & 9800 \\
\hline Neutrophils (\%) & 45 & 87 & 90 & 85 & 70 & 50 \\
\hline Hemoglobin (g/dl) & 15.1 & 12.9 & 13.0 & 14.1 & 14.0 & 14.9 \\
\hline Platelets $\left(10^{3} / \mathrm{mm}^{3}\right)$ & 690 & 555 & 505 & 410 & 350 & 250 \\
\hline C-reactive protein (mg/dl) & 0.1 & 1.2 & 13 & 21.9 & 11.5 & 0.5 \\
\hline Total proteins (g/dl) & 3.9 & 3.6 & 4.0 & 4.1 & 4.5 & 5.6 \\
\hline Albumin (g/dl) & 1.3 & 1.9 & 2.1 & 2.4 & 2.8 & 3.0 \\
\hline
\end{tabular}


stopped, and an intravenous infusion with a balanced electrolyte solution $(55 \mathrm{~mL} / \mathrm{h})$ was started. Serial surgical evaluations were performed in order to check the potential need for a surgical intervention, in case the conservative management turned out to be unsuccessful.

Just a few hours later, we assisted in a prompt improvement of the boy's general conditions and to a gradual disappearance of abdominal pain. The blood tests repeated at 24 and $48 \mathrm{~h}$ after the beginning of the antibiotic treatment showed an increase of infection markers, in spite of clinical improvement. A laboratory response started only after $72 \mathrm{~h}$ with a slow normalization of the tests within a week. Abdominal tenderness reduced gradually in the following days. Red umbilicus persisted for a week.

A Caucasian 4-year-old male was admitted to our unit due to periorbital swelling and edema of the sovrapubic region and of the legs that had lasted for 7 days. The patient had a past history of NS diagnosed 3 months earlier, for which he was treated with steroids. At the admission, vital signs were normal with a blood pressure of $85 / 45$ $\mathrm{mmHg}$. Laboratory investigations confirmed the clinical suspicion of a first relapse of his NS: total serum proteins $4.8 \mathrm{~g} / \mathrm{dl}$, albumin $2.1 \mathrm{~g} / \mathrm{dl}$, and urinary proteins $9.2 \mathrm{~g} /$ day $\left(920 \mathrm{mg} / \mathrm{m}^{2} / \mathrm{h}\right)$. He was treated with oral prednisone 60 $\mathrm{mg} / \mathrm{m}^{2} /$ day with a gradual but slow clinical and laboratory improvement. Eight days post-hospitalization, the child complained of diffuse and progressively worsening abdominal pain. Physical examination revealed a mildly distended abdomen with no palpable mass. The abdominal $\mathrm{X}$-ray ruled out a bowel obstruction or perforation. An abdominal ultrasound was performed being suggestive of ileo-ileal intussusception with a positive "target sign" (a single hypoechoic ring with a hyperechoic center) of 25 $\mathrm{mm}$ in diameter (Fig. 1).

In accordance with the pediatric surgeon and the pediatric radiologist, the child was managed conservatively because he was hemodynamically and clinically stable without any evidence of bowel perforation. Enteral feeding was stopped, and an intravenous infusion with a balanced electrolyte solution $(60 \mathrm{ml} / \mathrm{h})$ was started. A follow-up ultrasound done $24 \mathrm{~h}$ later showed a shorter invaginated segment ("target sign" of $16 \mathrm{~mm}$ ). After $48 \mathrm{~h}$ from the initial study, the ultrasound did not visualize the intussusception, which coincided with the NS remission.

\section{Discussion}

Primary peritonitis is a well-described infectious complication of NS. It usually occurs within the first 2 years of diagnosis, especially during relapse periods; its incidence is about $1.4-3.7 \%$ of children with NS, with a mortality rate of $9 \%$. Streptococcus pneumoniae is the most common organism causing bacterial peritonitis and sepsis in

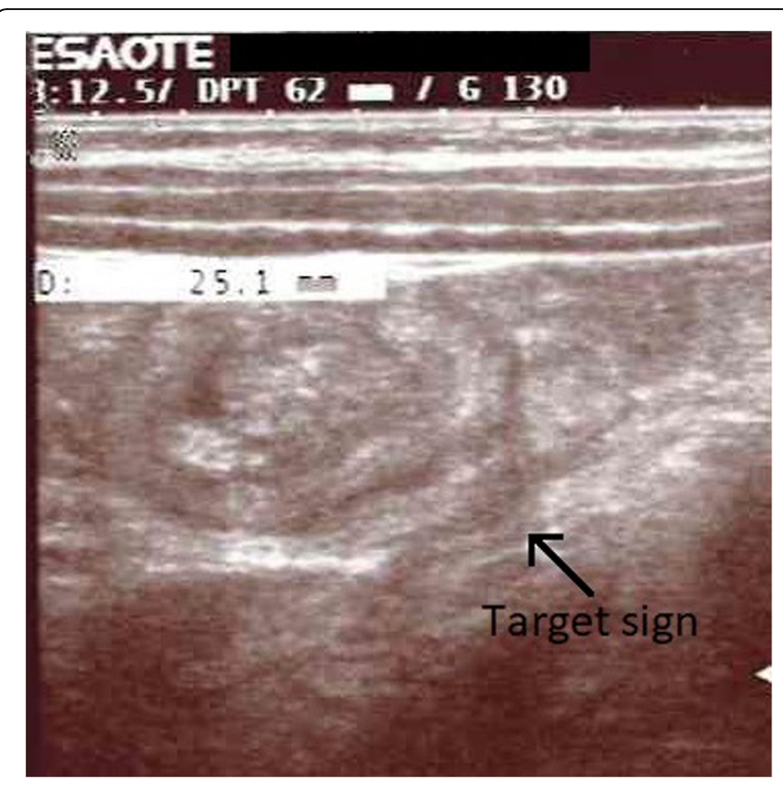

Fig. 1 Transverse ultrasonographic section of ileo-ileal intussusception producing the "target" sign (black arrow). The diameter of the lesion is $25 \mathrm{~mm}$

these patients [8-10]. In our first case, a Caucasian 4year-old boy with NS (fourth relapse) presented with abdominal pain, ascites, and red umbilicus. Our suspect of primary peritonitis was clinically confirmed because of the subsequent appearance of the classical peritoneal signs. Steroid treatment for NS is also likely to have led to a delayed diagnosis. Our patient was managed conservatively with empirical antibiotic therapy and with the continuous support of the pediatric surgical team, always ready for surgery in case of clinical deterioration. The diagnosis of peritonitis is only presumed in the absence of peritoneal fluid analysis: in many cases, a diagnostic paracentesis may not be available, and patients may be treated empirically with broad-spectrum antibiotics with the disadvantage of antibiotic resistance [8, 9]. Unfortunately, in our case, it was not possible to perform right away paracentesis, but the diagnosis was also eased suspected by the appearance of red umbilicus. Red umbilicus results from an inflammatory process that spreads to the subcutaneous fascial plane and infiltrates the umbilical skin. If unrecognized or untreated, the infection may complicate in a necrotizing fascitis of the abdominal wall with a high mortality rate. In the neonatal period, red umbilicus is often a troubling sign of infection, such as funisitis, omphalitis, or underlying gangrenous bowel and peritonitis like in the necrotizing enterocolitis [11, 12]. But among non-neonatal patients, red umbilicus is extremely rare as a sign of peritonitis. To our knowledge, this unusual presentation of red umbilicus caused by acute peritonitis in the non-neonatal period has rarely been reported [12-14]. 
In children with NS who present with abdominal pain, spontaneous bacterial peritonitis should be considered as the most important differential diagnosis [10], but it is not the only cause, as shown in Table 2 .

Intussusception represents one of the most frequent abdominal emergencies of infancy and early childhood and is characterized by bowel wall invaginating into another segment of the bowel. The classic symptomatology is intermittent abdominal pain, vomiting, and bloody stools, sometimes associated to a palpable right upper quadrant mass. The most common type of intussusception is ileocolic, and the majority of pediatric cases occur in patients $<1$ year of age. Intussusception has also been described as a rare but serious complication of NS and may present atypically unusual location (small bowel), absence of a palpable mass due to ascites, older age at presentation, and absence of the classic triad of symptoms [15]. The most popular hypothesis is that a combination of patchy bowel wall edema and peristaltic incoordination could provide the "pivot (lead point) and torque" in patients with NS $[16,17]$. It is possible that prolonged edema was the major cause of intussusception in our second patient, who developed acute abdominal pain after approximately 15 days of the NS relapse. It has been indeed reported that intussusception in NS may be due to generalized edema sustained for more than 2 weeks [18]. Treatments of ileocolic intussusception are nonoperative resolving procedures (air or barium contrast) and surgery (manual treatment with laparotomy). Ileoileal intussusception has no indication for radiological treatment, and given the frequent spontaneous resolution, it does not usually even require surgery. Treatments reducing bowel wall edema, such as infusion of albumin and diuretics, have been reported to play a significant role in the resolution of intussusception in NS as bowel wall edema would be the major cause of the condition, which is in contrast to typical intussusception [17]. In our case, it was very difficult to decide the treatment choice because the patient was clinically stable and a potential spontaneous reduction could not be ruled out. Furthermore, the intussusception interested the small bowel; Doi et al. first considered

Table 2 Causes of acute abdominal pain in nephrotic patients

\begin{tabular}{ll}
\hline Peritonitis & \\
\hline Intussusception & \\
Ischemic colitis & \\
Pneumatosis intestinalis & \\
Hypovolemic crisis & Eosinophilic gastroenteritis \\
Anecdotal & Congenital peritoneal encapsulation \\
& Splenic infarction \\
& Renal infarction \\
\hline
\end{tabular}

small bowel intussusception to be nonischemic and, therefore, benign and susceptible to spontaneous reduction [19]. Supported by the literature [15, 17, 19-21], we decided to adopt a conservative approach that led to a spontaneous reduction of intussusception. To our knowledge, this is one of the few pediatric cases of spontaneous resolution of intussusception in NS [15, 17]. The association between intussusception and NS was first reported in 1975 [22]. Subsequently, in the following 45 years, only 11 case reports have been described in the literature $[15,17,18,20-26]$. Characteristics of these patients are summarized in Table 3.

$M C D$ minimal change disease, $D M S$ diffuse mesangial sclerosis

Eight patients (73\%) were children at the time of intussusception, and surprisingly, only one case was younger than 1 year. Six of the 11 patients (55\%) presented intussusception during the first episode of NS, while 5 patients developed this disease-related complication during a relapse episode. All patients complained of abdominal pain; vomiting was reported in 5 cases $(45 \%)$, bloody stool in 3 cases (27\%), and a palpable abdominal mass (right upper quadrant) in 1 case (9\%). The intussusception occurred in an unusual location (small bowel) in 5 patients (45\%). Regarding the treatment, surgery was performed in 5 patients (45\%), whereas nonoperative resolving procedures were performed in 2 patients (18\%). Remarkably, a spontaneous reduction was observed in 4 patients (36\%); all of these cases were described in the last 10 years, after the first patient-reported by Cho et al. in 2009 [17].

Ischemic colitis is a disease caused by ischemia of the intestinal vessel, which presents with a sudden onset of abdominal pain and hematochezia. Diagnosis is confirmed by colonoscopy. Although thromboembolism is an important and frequent complication in patients with NS (presumably attributable to a hypercoagulable state), reports of ischemic colitis in the setting of NS are extremely rare, and only 3 cases ( 2 adults and 1 child) have been reported [27-29]. About our first patient, we ruled out the suspect of ischemic colitis because the child never showed bloody diarrhea or suggestive radiological signs. In regard to the mild increase of blood D-dimer we found, it is been described that its rise is not exclusively a marker of thromboembolic disease but can be an expression of other conditions, such as infections or inflammation [30].

Pneumatosis intestinalis is another rare cause of abdominal pain in nephrotic patients, described in 3 adults and 1 child [31-34]. It is a condition characterized by the linear or cystic accumulation of gas within the gastrointestinal wall. Patients may be asymptomatic or present with bloody diarrhea, abdominal pain, abdominal distension, constipation, and tenesmus from rectal 


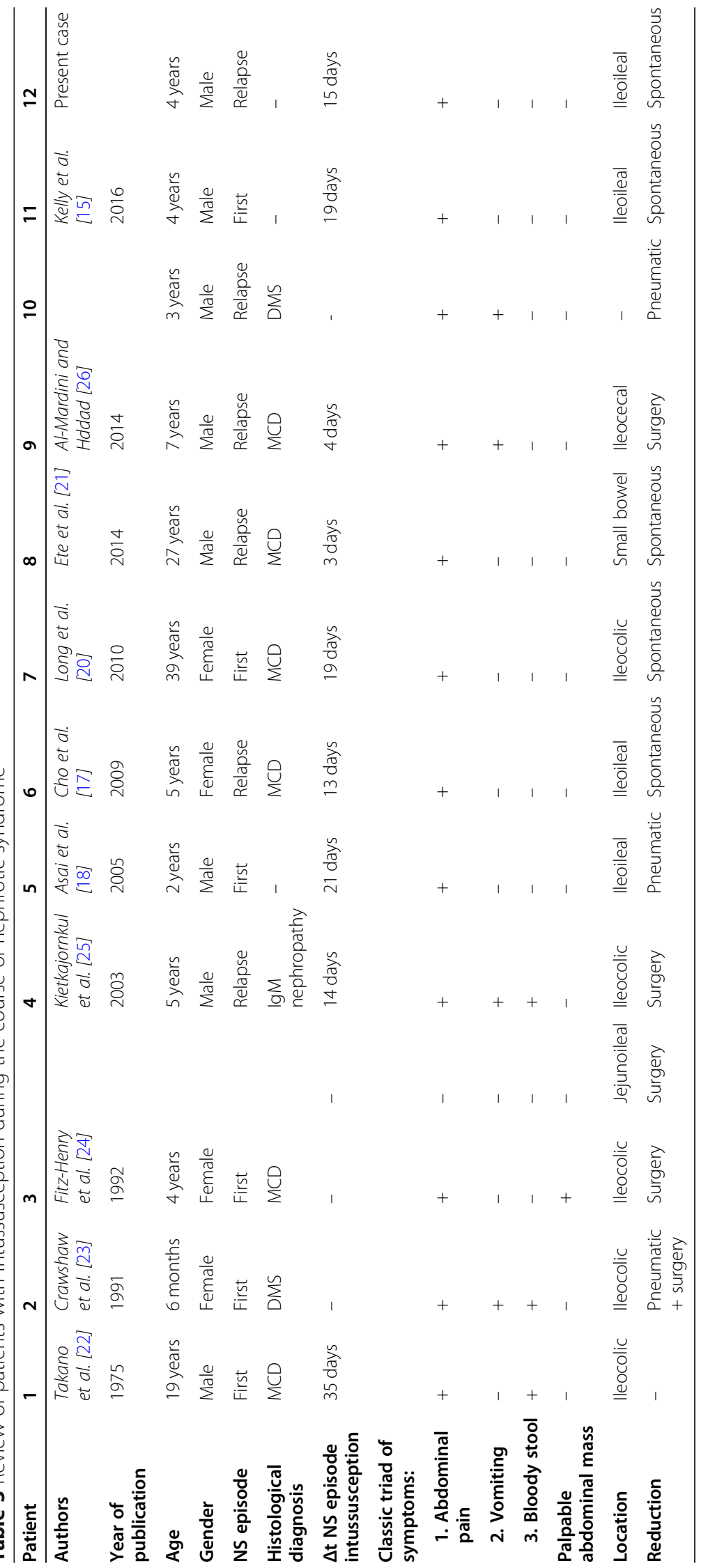


involvement. Gut edema, the use of immunosuppressive agents, and preceding viral gastroenteritis are possible predisposing factors [31].

As pointed out by Wang et al. [35], abdominal pain may also be a symptom of the hypovolemic state (hypovolemia-induced ischemia) in children with NS. Hypovolemic crises typically occur early in the course of NS (first episode or relapse), even before edema is evident [36, 37].

Finally, few case reports documented the association between NS and other causes of abdominal pain: eosinophilic gastroenteritis (a rare disease characterized by prominent eosinophilic tissue infiltration of the gastrointestinal tract) [38], congenital peritoneal encapsulation (an accessory peritoneal flap that encloses the entire mass of the small intestine) [39], splenic infarction [4042], and renal infarction [43, 44] (as a thromboembolic complication).

\section{Conclusions}

We reported 2 cases of pediatric patients suffering from NS who developed peritonitis (first case) and intussusception (second case) during a relapse episode. The most remarkable manifestation in our patients was the acute abdominal pain; the appearance of this symptom in the setting of NS requires prompt management, both clinical and instrumental. A close collaboration between a pediatric nephrologist and a pediatric surgeon may be necessary to lead to an accurate diagnosis and a correct treatment. Acute abdominal pain in NS is usually related to infectious peritonitis. The presence, although rare, of red umbilicus may be a suggestive sign of peritonitis also in non-neonatal period. Intussusception is an infrequent complication but should be considered among the complications of NS, especially in patients with prolonged edema. These two cases demonstrate the frequent surgical complications in nephrotic patients. Nevertheless, our experience shows how clinical management, together with tight surgical consulting, can represent a successful option of treatment.

\section{Abbreviations}

NS: Nephrotic syndrome; MCD: Minimal change disease; DMS: Diffuse mesangial sclerosis

\section{Acknowledgements}

Not applicable

\section{Authors' contributions}

GC and RC had the idea for the article. CV performed the literature search. NSC and VC wrote the first draft of the manuscript. PI, CV, and CR critically revised the work. All authors have read and agreed to the published final version of the manuscript. The author(s) read and approved the final manuscript.

\section{Funding}

No funds, grants, or other support was received.

Availability of data and materials

Not applicable

\section{Declarations}

Ethics approval and consent to participate

Not applicable

\section{Consent for publication}

Parents signed an informed consent regarding publishing the data and photographs of their children.

\section{Competing interests}

The authors declare that they have no competing interests.

\section{Author details}

${ }^{1}$ Pediatric Nephrology and Rheumatology Unit, Department of Human Pathology in Adult and Developmental Age "Gaetano Barresi," AOU Gaetano Martino, University of Messina, Via Consolare Valeria, 98124 Messina, Italy. ${ }^{2}$ Pediatric Surgery Unit, Department of Human Pathology in Adult and Developmental Age "Gaetano Barresi", University of Messina, Messina, Italy. ${ }^{3}$ Division of Radiology, Department of Biomedical and Dental Sciences and Morphofunctional Imaging, University of Messina, Messina, Italy.

Received: 20 April 2021 Accepted: 10 September 2021

Published online: 01 December 2021

\section{References}

1. Pasini A, Benetti E, Conti G, Ghio L, Lepore M, Massella L, et al. The Italian Society for Pediatric Nephrology (SINePe) consensus document on the management of nephrotic syndrome in children: part I - diagnosis and treatment of the first episode and the first relapse. Ital. J. Pediatr. 2017;43(1): 41. https://doi.org/10.1186/s13052-017-0356-x.

2. Pasini A, Aceto G, Ammenti A, Ardissino G, Azzolina V, Bettinelli A, et al. Best practice guidelines for idiopathic nephrotic syndrome: recommendations versus reality. Pediatr Nephrol. 2015;30(1):91-101. https://doi.org/10.1007/ s00467-014-2903-7.

3. Conti G, De Vivo D, Fede C, Arasi S, Alibrandi A, Chimenz R, et al. Low birth weight is a conditioning factor for podocyte alteration and steroid dependance in children with nephrotic syndrome. J Nephrol. 2018;31(3): 411-5. https://doi.org/10.1007/s40620-018-0473-7.

4. Siligato R, Cernaro V, Nardi C, De Gregorio F, Gembillo G, Costantino G, et al. Emerging therapeutic strategies for minimal change disease and focal and segmental glomerulosclerosis. Expert Opin Investig Drugs. 2018;27(11): 839-79. https://doi.org/10.1080/13543784.2018.1540587.

5. Noone DG, lijima K, Parekh R. Idiopathic nephrotic syndrome in children. Lancet. 2018;392(10141):61-74. https://doi.org/10.1016/S0140-6736(18)3053 6-1.

6. Park SJ, Shin Jl. Complications of nephrotic syndrome. Korean J Pediatr. 2011;54(8):322-8. https://doi.org/10.3345/kjp.2011.54.8.322.

7. Long EB, Coyle J, Plant WD, Barry J, Browne S. Intussusception of the small bowel in an adult associated with nephrotic syndrome. NDT Plus. 2010;3(5): 505-6. https://doi.org/10.1093/ndtplus/sfq114.

8. Uncu N, Bülbül M, Yildiz N, Noyan A, Koşan C, Kavukçu S, et al. Primary peritonitis in children with nephrotic syndrome: results of a 5-year multicenter study. Eur J Pediatr. 2010;169(1):73-6. https://doi.org/10.1007/ s00431-009-0989-x.

9. Hingorani SR, Weiss NS, Watkins SL. Predictors of peritonitis in children with nephrotic syndrome. Pediatr Nephrol. 2002;17(8):678-82. https://doi.org/10.1 007/s00467-002-0890-6.

10. Teo S, Walker A, Steer A. Spontaneous bacterial peritonitis as a presenting feature of nephrotic syndrome. J Paediatr Child Health. 2013:49(12):1069-71. https://doi.org/10.1111/jpc.12389.

11. Henbest DM, Steele RW. Periumbilical erythema in a neonate. Clin Pediatr (Phila). 2013;52(4):374-7. https://doi.org/10.1177/0009922813479167.

12. Chang YT, Lin JY. Red umbilicus as a clinical manifestation in a 19-monthold girl with typhoid colonic perforation. Kaohsiung J Med Sci. 2007;23(2): 80-3. https://doi.org/10.1016/S1607-551X(09)70379-1.

13. Tazi F, Ahsaini M, Khalouk A, Mellas S, Stuurman-Wieringa RE, Elfassi MJ, et al. Abscess of urachal remnants presenting with acute abdomen: a case series. J Med Case Rep. 2012;30(1):226. https://doi.org/10.1186/1752-19476-226.

14. Naseri M. Pneumococcal sepsis, peritonitis, and cellulitis at the first episode of nephrotic syndrome. Iran J Kidney Dis. 2013;7(5):404-6. 
15. Kelly GS, Brady TM. A child with nephrotic syndrome and abdominal pain. Clin Pediatr (Phila). 2016;55(7):683-5. https://doi.org/10.1177/000992281 5598861.

16. Reymond RD. The mechanism of intussusception: a theoretical analysis of the phenomenon. Br J Radiol. 1972;45(529):1-7. https://doi.org/10.1259/ 0007-1285-45-529-1.

17. Cho MH, Hwang HH, Choe BH, Kwon SH, Ko CW, Kim JY, et al. The reversal of intussusception associated with nephrotic syndrome by infusion of albumin. Pediatr Nephrol. 2009;24(2):421-2. https://doi.org/10.1007/s00467008-1019-3.

18. Asai K, Tanaka S, Tanaka N, Tsumura K, Kato F, Kikuchi K. Intussusception of the small bowel associated with nephrotic syndrome. Pediatr Nephrol. 2005; 20(12):1818-20. https://doi.org/10.1007/s00467-005-2050-2.

19. Doi O, Aoyama K, Hutso JM. Twenty-one cases of small bowel intussusception: the pathophysiology of idiopathic intussusception and the concept of benign small bowel intussusception. Pediatr Surg Int. 2004;20(2): 140-3. https://doi.org/10.1007/s00383-003-1055-9.

20. Long EB, Coyle J, Plant WD, Barry J, Browne S. Intussusception of the small bowel in an adult associated with nephrotic syndrome. NDT Plus. 2010;3: 505-6.

21. Ete T, Mondal S, Sinha D, Nag A, Chakraborty A, Pal J, et al. Small bowe intussusception in an adult with nephrotic syndrome. Indian J Nephrol. 2014;24(2):136-7. https://doi.org/10.4103/0971-4065.127930.

22. Takano T, Nakagawa M, Ishiwara H. Jaundice, vomiting and abdominal pain (nephrotic syndrome): intussusception (with lipoid nephrosis). Nihon Rinsho. 1975:1502-5.

23. Crawshaw PA, Watson AR, Rance $\mathrm{CH}$. Intussusception nephrosis and Drash syndrome. Eur J Pediatr. 1991;150(11):813-4. https://doi.org/10.1007/BF0202 6719.

24. Fitz-Henry J, Watson AR, Rance $\mathrm{CH}$, Broderick NJ. Intussusception associated with nephrotic syndrome. Br J Surg. 1992;79(11):1201. https://doi.org/10.1 002/bjs.1800791134.

25. Kietkajornkul C, Vithayasai N, Ratanaprakarn W, Buranakitjaroen V. Intussusception associated with a relapsing nephrotic patient: a case report. J Med Assoc Thai. 2003;86:596-9.

26. Al-Mardini Rl, Haddad RE. Intussusception in two pediatric patients associated with nephrotic syndrome. Saudi J Kidney Dis Transpl. 2014;25(2): 398-401. https://doi.org/10.4103/1319-2442.128584.

27. Yanagisawa A, Namai Y, Sekine T, Igarashi T. Ischemic colitis as a complication in a patient with steroid-dependent nephrotic syndrome. Pediatr Nephrol. 2008;23(4):655-7. https://doi.org/10.1007/s00467-0070665-1.

28. Yasumori R, Shibata T, Nasu M, Ohzono Y, Harada T, Hara K. A case of nephrotic syndrome associated with ischemic colitis exhibiting thickening of the colon wall. Jpn J Nephrol. 1995;37:348-52.

29. Rodriguez MA. Ischemic colitis and malignant atrophic papulosis. Am J Gastroenterol. 1977;67(2):163-6.

30. $\mathrm{Ho} \mathrm{CH}$. Can very high level of D-dimer exclusively predict the presence of thromboembolic diseases? J Chin Med Assoc. 2011;74(4):151-4. https://doi. org/10.1016/j.jcma.2011.01.034.

31. Chan WK, Lee KW, Fan TW. Pneumatosis intestinalis in a child with nephrotic syndrome and norovirus gastroenteritis. Pediatr Nephrol. 2010; 25(8):1563-6. https://doi.org/10.1007/s00467-010-1478-1.

32. Maeda $Y$, Inaba N, Aoyagi M, Kanda E, Shiigai T. Fulminant pneumatosis intestinalis in a patient with diabetes mellitus and minimal change nephrotic syndrome. Intern Med. 2007;46(1):41-4. https://doi.org/10.2169/ internalmedicine.46.6076.

33. Han BG, Lee JM, Yang JW, Kim MS, Choi SO. Pneumatosis intestinalis associated with immune-suppressive agents in a case of minimal change disease. Yonsei Med J. 2002;43(5):686-9. https://doi.org/10.3349/ymj.2002.43. 5.686 .

34. litsuka T, Kobayashi M, Izumi Y, Koyama A. Pneumatosis cystoides intestinalis following steroid treatment in a nephrotic syndrome patient: report of a case. Nihon Jinzo Gakkai Shi. 1993;35(3):293-7.

35. Wang SJ, Tsau YK, Lu FL, Chen CH. Hypovolemia and hypovolemic shock in children with nephritic syndrome. Acta Pediatr Taiwan. 2000;41:179-83.

36. Amil B, Santos F, Ordoñez FA, Martínez V, Málaga S. Severe acute abdominal pain in a patient with steroid-sensitive idiopathic nephrotic syndrome. Pediatr Nephrol. 2002;17(10):875-6. https://doi.org/10.1007/s00467-0020958-3.
37. Theuns-Valks SD, Van Wijk JA, Van Heerde M, Dolman KM, Bökenkamp A. Abdominal pain and vomiting in a boy with nephrotic syndrome. Clin Pediatr (Phila). 2011;50(5):470-3. https://doi.org/10.1177/0009922810361366.

38. Choi DM, Pyun JE, Yim HE, Yoo KH, Shim JO, Lee EJ, et al. Eosinophilic gastroenteritis in an 18-year-old male with prolonged nephrotic syndrome. Korean J Pediatr. 2016;59(Suppl 1):S72-5. https://doi.org/10.3345/kjp.2016. 59.11.S72.

39. Torsello A, Cioffi A, Tomassini L, Filograna C, De Salazar C, Aromatario M. Congenital peritoneal encapsulation and nephrotic syndrome. J Forensic Sci. 2020. Epub ahead of print. doi: https://doi.org/10.1111/1556-4029.14292, Withdrawal: Torsello A, et al. Congenital Peritoneal Encapsulation and Nephrotic Syndrome. J Forensic Sci 2020 (https://onlinelibrary.wiley.com/ doi/10.1111/1556-4029.14292), 65, 3, 1026.

40. Wang CC, Tung WC, Ng HY, Lee WC, Tsai YC, Chuang FR, et al. Splenic infarction as a cause of acute abdominal pain in nephrotic syndrome. Nephrology (Carlton). 2009;14:623.

41. Li QY, Yang YJ, Chen QK. Splenic infarction as starting symptom in minimal change nephropathy. Chin Med J. 2017;130(5):621-2. https://doi.org/10.41 03/0366-6999.200552.

42. Famularo G, Cortese A. Splenic infarction: a dark side of the nephrotic syndrome. Am J Med. 2020;133(3):e106-7. https://doi.org/10.1016/j.a mimed.2019.10.014.

43. Nandwani A, Pathania D, Jha PK, Kher V. Renal artery thrombosis with renal infarction: a rare cause of acute abdomen. Indian J Nephrol. 2017;27(4):3135. https://doi.org/10.4103/0971-4065.183581.

44. Sugimoto K, Iba Y, Fujita S, Sakata N, Okada M, Takemura T. Nephrotic syndrome complicated by renal and cerebral infarctions in a 14-year-old girl. Pediatr Int. 2012;54(4):549-52. https://doi.org/10.1111/j.1442-200X.2011. 03552.x.

\section{Publisher's Note}

Springer Nature remains neutral with regard to jurisdictional claims in published maps and institutional affiliations.

\section{Submit your manuscript to a SpringerOpen ${ }^{\circ}$ journal and benefit from:}

- Convenient online submission

- Rigorous peer review

- Open access: articles freely available online

- High visibility within the field

- Retaining the copyright to your article

Submit your next manuscript at $>$ springeropen.com 